\title{
DESIGN E ARTE URBANA: PAISAGEM MODIFICADA
}

Rosilene Conceição Maciel

Universidade do Estado de Minas Gerais

rmaciela@gmail.com

Rita de Castro Engler

Universidade do Estado de Minas Gerais

rcengler@uol.com

Manoela Tarcila Martins Rosa

Universidade do Estado de Minas Gerais

manoela.tarcila@gmail.com

Resumo: A proposta deste trabalho convida a uma análise sobre a influência mútua que se estabelece entre o design e a arte urbana. Discute as intervenções visuais que se sobrepõem no cenário da cidade entre críticas sociais, manifestos e outras formas de expressão. Apresenta resultados parciais de um projeto de pesquisa que visa gerar um acervo de imagens de intervenções gráfico-visuais no Baixo Centro e na região da Pampulha em Belo Horizonte para posterior análise comparativa das regiões pela disparidade social, cultural e econômica que apresentam. Além do referencial teórico, utiliza como técnica de coleta de dados o registro fotográfico com base em roteiros pré-definidos e publicações em mídias sociais. Este artigo, visa iniciar uma discussão sobre a dinâmica das intervenções e manifestações visuais urbanas, pelos registros de ações expressas nas ruas da cidade em constante movimentação, dando a elas maior visibilidade, alcance e reflexão acerca dos significados estéticos, subjetivos e ideológicos que carregam.

Palavras-chave: Design, arte urbana, paisagem, Belo Horizonte.

Abstract: The proposal of this article invites for an analysis about the mutual influence that is established between design and street art. It discusses the visual interventions that overlap in the scenario of the city between social criticism, manifests and other forms of expression. It presents partial results of a research project that aims to generate a stock of images from graphic-visual interventions in both the downtown area and the region of Pampulha in Belo Horizonte, for further comparative analysis the regions with considerable social, cultural and economic disparity. In addition to the theoretical framework, it uses as a data collection method the photographic record, based on well-marked scripts and records in social media. This article, aims to set off a discussion on the dynamics of interventions and urban visual manifestations, by the records of actions 
expressed in the streets of the city, which constant movement gives them greater visibility, reach and reflection on the aesthetic, subjective and ideological meanings they carry.

Keywords: Design, urban art, landscape, Belo Horizonte.

\section{INTRODUÇÃO}

As cidades contemporâneas, especialmente as grandes cidades, tem sido palco de variadas formas de manifestações artísticas interagindo com a paisagem urbana e com o cotidiano das pessoas. Tornaram-se híbridas, influenciadas por múltiplas referências estéticas, simbólicas e históricas. A cada dia se renovam, se reinventam e atraem novos olhares.

Neste artigo apresentam-se resultados parciais da proposta de criar um acervo de imagens das intervenções visuais urbanas na região da Pampulha e do Baixo Centro de Belo Horizonte para, posteriormente, estabelecer uma análise comparativa das imagens sob a perspectiva das artes visuais e do design como mediadores da cultura e potencializadores dos múltiplos discursos da cidade.

Parte-se do pressuposto de que a paisagem construída é resultado dos contextos culturais que marcam os diferentes territórios que constituem a cidade. As expressões materializadas nos muros, paredes e viadutos urbanos, podem revelar, em parte, diferentes identidades, valores e anseios que se sobrepõem no cenário urbano.

Diante da efemeridade desse tipo de intervenção urbana, o registro das imagens é de grande importância para referenciar as pesquisas nesse campo. Além da natureza dinâmica que Ihe é característica, há também a atuação dos meios de controle do poder público, que eventualmente podem nelas intervir ou mesmo excluí-las.

A constituição do acervo visa contribuir com os estudos da arte urbana na cidade de Belo Horizonte, na construção das relações com o design gráfico, favorecendo a continuidade e desdobramentos desse debate da academia com a sociedade.

Somando aos estudos de referências bibliográficas, como método de coleta de dados estão previstos registros periódicos em pontos específicos, eleitos para o acompanhamento das alterações e sobreposição de imagens, ou mesmo intervenções em artes anteriores. Atualmente, as mídias sociais são uma fonte de pesquisa e também serão consultadas ao longo deste trabalho.

Espera-se obter como resultado um acervo relevante que possibilite uma análise comparativa ao longo do processo e também entre as regiões delimitadas para o estudo.

\section{A DINÂMICA VISUAL DA PAISAGEM URBANA}

As paisagens urbanas disputam a visualidade em meio à trama híbrida no cotidiano. O cenário urbano está sujeito a novas apreensões e disputas constantes de interesses e lutas semânticas que o modificam do ponto de vista concreto e também conceitual, intelectual. "No movimento da cidade, os interesses mercantis cruzam-se com os históricos, estéticos e comunicacionais" (CANCLINI, 2001, p. 301). 
A partir dos anos de 1960, de acordo com Archer (2001), o cenário e os meios tradicionais de expressão artística deram lugar às experimentações técnicas, novos procedimentos, materiais e suportes. As formas de expressão contemporâneas incluem práticas hibridas, influenciadas por múltiplas referências estéticas, simbólicas e históricas. Extrapolam os meios de controle e centralização e interagem com a paisagem no dia a dia das pessoas.

São produtos urbanos de múltiplas linguagens, formas, leituras e significados que agregam diferentes vozes, intenções, modos de ver, viver, usar e reinventar a cidade. Nesse contexto, de acordo com Pallamin, (2000), a cidade transforma-se, em documento histórico e em galeria a céu aberto e deve ser entendida como tal. A arte e o design urbanos tornam-se integrantes do cotidiano da cidade e são "consumidos" quase desapercebidamente.

As ruas da cidade tornam-se suporte de manifestações ideológicas, expressas e materializadas em muros, postes, viadutos, dividindo espaço com todo o aparato de interesses diversos, consumo, publicidade e velocidade que caracterizam os grandes centros urbanos. Featherstone (1995), citado por Lemos (2010), alerta que o consumo nas grandes cidades vai além de produtos e valores de uso, de utilidades materiais. Para o autor, consomem-se primordialmente signos. Para Brissac (1992),

\begin{abstract}
Nas cidades, os olhos não veem coisas, mas figuras de coisas que significam outras coisas. Ícones, estátuas, tudo é símbolo. Signos urbanos, como placas, letreiros, anúncios, grafites... tudo é linguagem, tudo se presta à descrição, ao mapeamento da cidade. O olhar percorre as ruas como páginas escritas, a cidade diz como se deve lê-la. Como é realmente a cidade sob esse carregado invólucro de símbolos, o que conta e o que esconde, parece impossível de saber (BRISSAC, 1992, p. 311).
\end{abstract}

A cidade, como portadora de múltiplos discursos, revela identidades que se convergem e se divergem em meio à diversidade e complexidade de sua realidade. 0 cidadão é ao mesmo tempo leitor e escritor, agente e intérprete dos signos, podendo transformar a paisagem urbana e por ela se deixar ser transformado.

\title{
2.10 design e a arte visual urbana
}

O design é uma atividade que leva em consideração o ser humano e suas produções, usos e significados, seu local de convivência, cultura e modos de vida dentre outros fatores. A concepção contemporânea de design amplia sua atuação no âmbito social e estreita a sua relação com a cultura. De forma crescente, suas ações são orientadas a modos de viver valorizando a experiência e as emoções,

O design e as artes estão presentes na funcionalidade dos espaços e na visualidade da cidade em suas sutilezas, em suas poéticas. São mediadores da cultura e dialogam constantemente em uma influência mútua. Para Velasco (2013), esse diálogo tornou-se mais evidente a partir da década de 70, quando o estilo da vida das ruas, contrariando velhas convenções sociais, foi incorporado à música, à moda, e aos projetos de design por uma geração criativa e independente, livre das amarras e ditames socioculturais.

A mudança mais significativa proporcionada por esta geração de artistas ocorreu dentro da estrutura de compra e venda de arte. E o principal fator que possibilitou esta transformação foi sem dúvida alguma combinação 
Arte e design se misturam e emprestam sua estética às ruas em formas de grafites, lambe-lambes, pôsteres e tantos outros. De modo geral, as intervenções visuais urbanas, são ações quase sempre efêmeras resultantes de manifestações culturais com objetivos de interagir e comunicar com a cidade e seus cidadãos. Uma intervenção pode durar o tempo em que a imagem ficar na memória de quem a viu ou o tempo em que as histórias de seus desdobramentos forem contadas.

Como diretrizes, as intervenções visuais urbanas buscam trazer à tona aspectos da vida urbana que se tornam invisíveis pela aceleração dos grandes centros. Estabelecem discussões sobre os problemas sociais e urbanos convidando à reflexões sobre a realidade e, por outro lado, reivindicam a cidade como espaço para a arte, numa visão mais poética e lançando mão de meios populares e compartilhados na realização de trabalhos.

Nas grandes cidades estão presentes diferentes tipologias de intervenções urbanas gráfico-visuais do tipo artísticas, urbanísticas, comerciais; e podem ser aplicadas em muros, paredes, postes, orelhões, portas, praças, viadutos entre outros. São variadas formas de expressão artística que se renovam e revelam as cidades nos lugares do cotidiano, antes não notados, e que ganham novos significados a cada nova paisagem modificada pelas mãos de artistas visuais, designers e pessoas comuns que vivenciam a cidade.

A proposta deste trabalho é suscitar um debate sobre a relação do design com a ocupação gráfico-visual dos espaços urbanos, seu caráter reivindicatório e de denúncia, onde diferentes vozes se sobrepõem nos muros da cidade. Inicialmente o estudo envolve duas localidades de Belo Horizonte: o baixo centro cultural da cidade e a região norte de Belo Horizonte em função das diferenças sociais, culturais e econômicas.

\subsection{A paisagem do Baixo Centro de $\mathrm{BH}$}

A imagem abaixo (figura 1) mostra intervenções feitas próximas ao viaduto Santa Tereza, na região central de Belo Horizonte, onde coexistem intervenções com diferentes temáticas, recursos e linguagem visual.

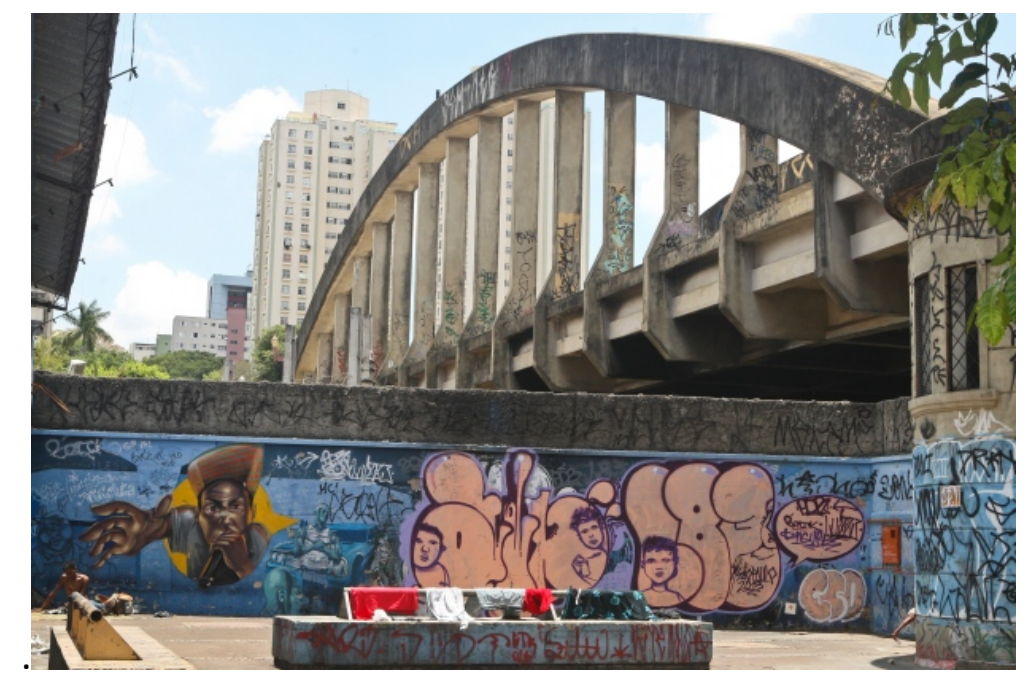

Figura 1 - Grafite no centro de BH próximo ao viaduto Santa Tereza - Autoria não identificada Fonte: http://www.otempo.com.br. Foto de Mariela Guimaraes. Acesso 07/04/2016 
A região do baixo centro de Belo Horizonte marca o início da fundação e construção da cidade e possui grande relevância histórica. Era um ponto marcante na capital em função da Estação Ferroviária Central que concentrava todo o movimento de entrada e saída da cidade. Mas, de acordo com Jaime e Trevisan (2012), ao final do século XX, a região perdeu essa função, que passou a ser exercida pela rodoviária e pelo aeroporto entrando em processo de decadência e abandono por parte poder público. Nas últimas décadas, a região voltou a receber investimentos que visam sua revitalização como forma de atrair, novamente, o circuito superior da economia ao baixo centro (ROBERTI, 2014). Em paralelo, e até mesmo em consequência deste investimento, a região transformou-se em palco de muitas manifestações artísticoculturais e intervenções visuais que denotam a apropriação espontânea do espaço, particularmente na Rua Aarão Reis, próximo ao viaduto Santa Tereza, onde predomina um manifesto livre, diverso e transgressor como mostram as imagens abaixo:

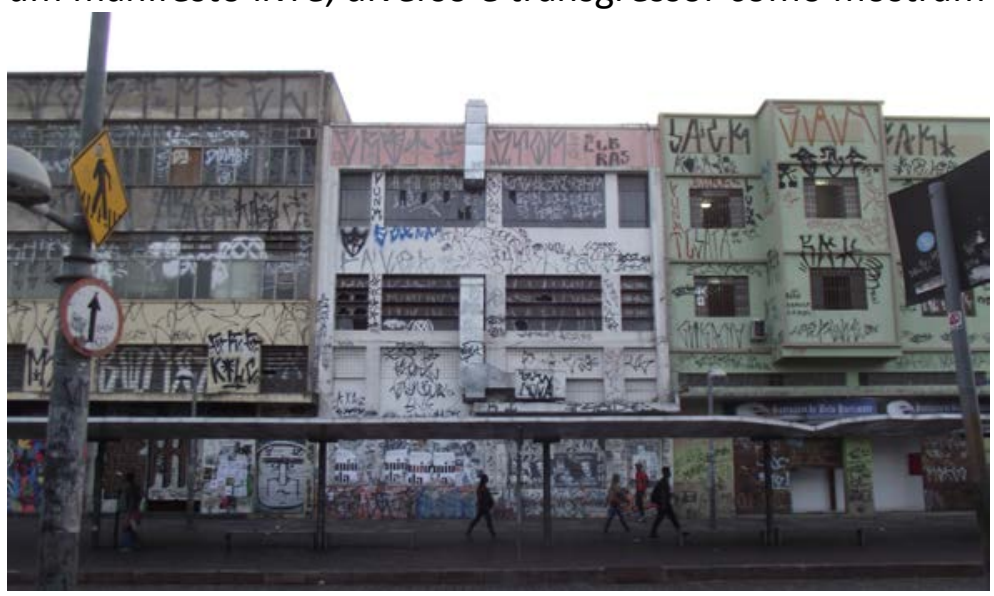

Figura 2 - Fachada de edificações localizadas à Rua Aarão Reis.

Fonte: Foto das autoras - 17/05/16.

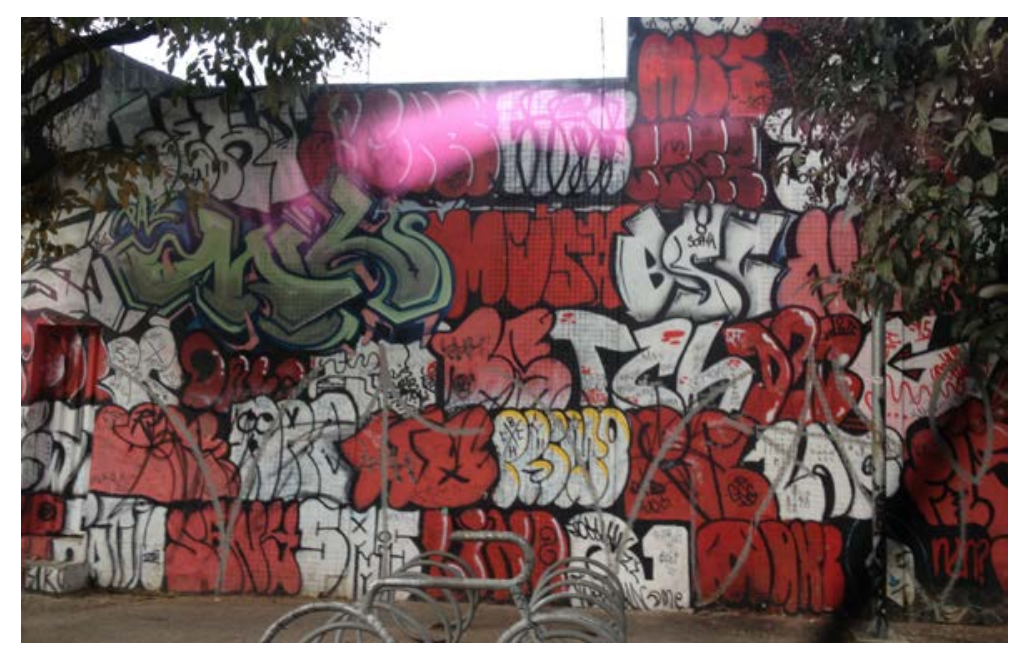

Figura 3 - Grafite em muro à Rua Aarão Reis

Fonte: Foto das autoras - 17/05/16. 


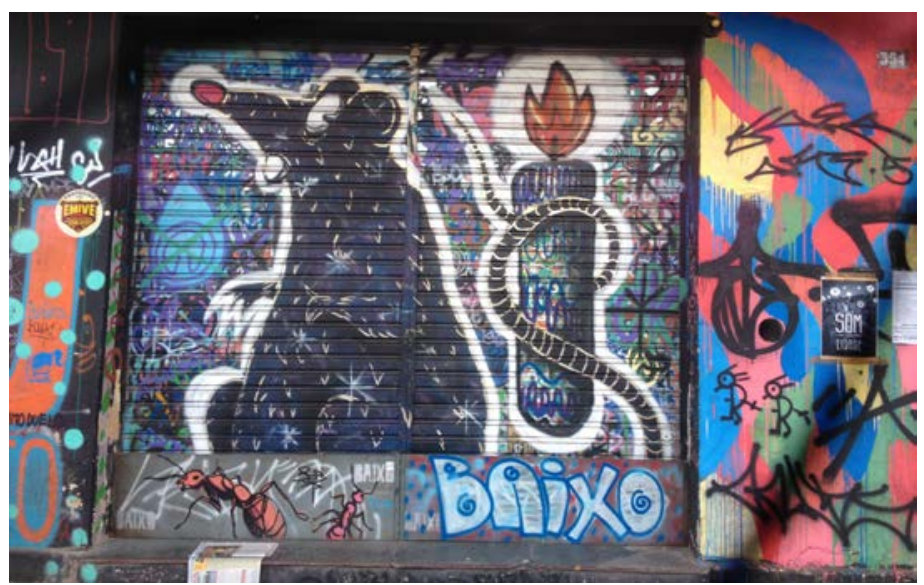

Figura 4 - Grafite na porta do “Baixo”. Bar localizado à Rua Aarão Reis.

Fonte: Foto das autoras - 17/05/16.

\subsection{O projeto Telas Urbanas na região da Pampulha}

O projeto "Telas Urbanas" foi uma iniciativa da Prefeitura de Belo Horizonte (PBH), coordenado pela Fundação Municipal de Cultura (FMC) e realizado pelo Museu de Arte da Pampulha (MAP), em parceria com a Associação Cultural dos Amigos do Museu de Arte da Pampulha (AMAP). "com o objetivo requalificar espaços urbanos, públicos ou privados, por meio da arte mural". (PMBH, Publicado em 09/10/2015).

Dividido em duas etapas contou com a participação de artistas selecionados via edital e também de artistas convidados. A primeira fase foi executada entre os dias 16 e 22 de novembro de 2015, e a segunda fase entre 29 de março e 04 de abril de 2016. Os trabalhos foram realizados em muros e fachadas previamente definidos na Av. Antônio Carlos e na Av. Pedro I, ambas localizadas na Pampulha, região norte de Belo Horizonte.

Os projetos foram inscritos de acordo com duas categorias (1 e 2) que delimitavam a área de intervenção em 12 ou $24 \mathrm{~m} 2$ de acordo com o portfólio apresentado pelo artista. As artes foram planejadas, projetadas e previamente selecionadas segundo critérios definidos em editais pelo projeto Telas Urbanas para aplicações em muros, fachadas, painéis, tapumes e afins.

Abaixo, a figura 5 mostra um grafite, integrante do projeto Telas Urbanas, em fase final de execução. No canto inferior esquerdo está a identificação do projeto. Na imagem, é possível perceber a estrutura dos andaimes utilizada na execução do trabalho, realizado na Av. Antônio Carlos.

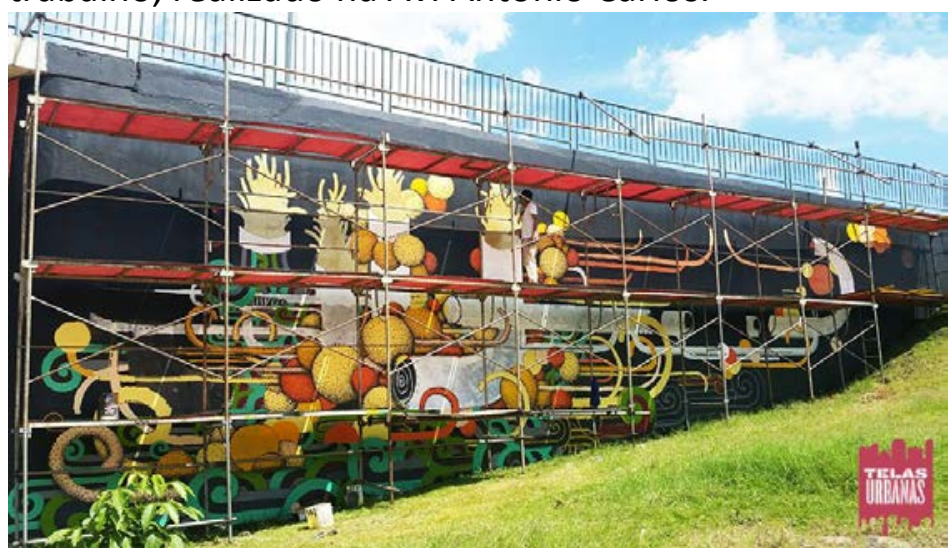

Figura 5 - Trabalho de Thiago Alvin - Projeto "Telas Urbanas" - Região norte de BH. Av. Antônio Carlos Fonte: Facebook Museu de Arte da Pampulha - Acesso em 07/04/2016. 
A região da Pampulha desenvolveu-se especialmente a partir da década de 30 com a expansão e horizontalização da cidade. Foi idealizada como lugar de lazer, com área verde em contraposição à crescente industrialização e verticalização de Belo Horizonte à época (Carsalade, 2006).

Região nobre da cidade, a Pampulha possui importantes obras que formam um conjunto arquitetônico e artístico, além de um sofisticado complexo de lazer e turismo, traduzido pelas construções do Cassino, do late Golfe Club, da Casa do Baile e da Igreja de São Francisco de Assis. No Complexo Urbanístico da Pampulha encontramse as obras de Niemeyer e de artistas brasileiros como Alfredo Cheschiatti, Burle Marx, Paulo Werneck e Cândido Portinari. Enquanto estética moderna, o Complexo Urbanístico da Pampulha, inaugurou na cidade uma paisagem singular. Em 2016, a Organização das Nações Unidas para a Educação, Ciência e Cultura (Unesco) reconheceu o conjunto moderno da Pampulha como Patrimônio Cultural da Humanidade.

Na década de 50, integrada ao centro da cidade pela Av. Pampulha (atual Av. Antônio Carlos) a região da Pampulha recebeu o campus da Universidade Federal de Minas Gerais e outras instalações dinamizando o movimento urbano e dando também início à ampliação demográfica na região. Apesar do crescimento desordenado, problemas de assoreamento da lagoa e trânsito intenso, possui ainda uma das mais belas paisagens de cartão postal da cidade. Cenário escolhido para a o projeto Telas Urbanas.

Dentre os trabalhos selecionados e executados no Projeto Telas Urbanas, será destacado nesse artigo o trabalho de Felipe Nogueira Godoy (Efe Godoy) realizado na Av. D. Pedro I (Muros da Vila Olímpica do Clube Atlético Mineiro).

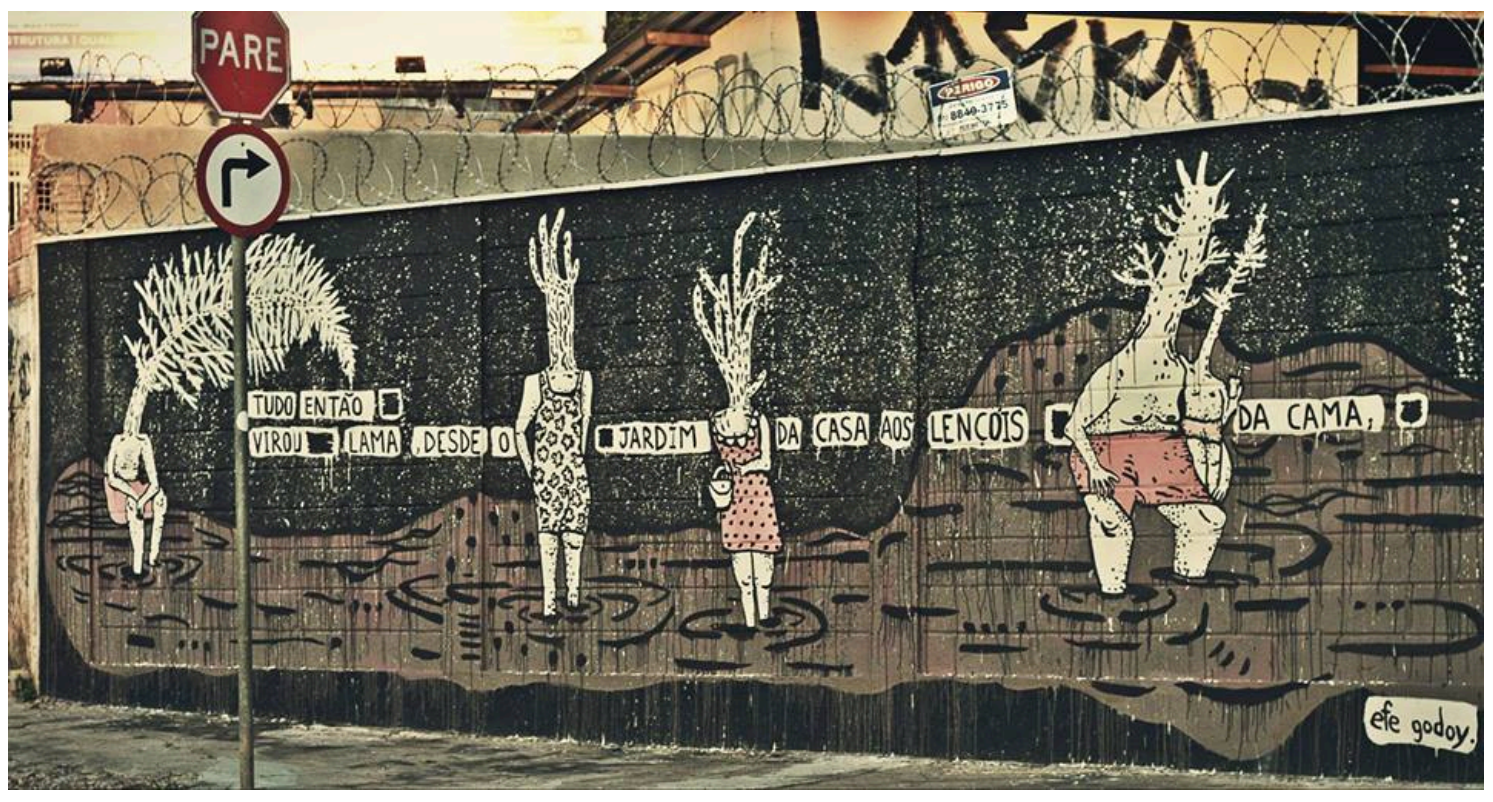

Figura 6 - Trabalho original “Telas Urbanas” de Felipe Nogueira Godoy (Efe Godoy). Fonte: Facebook do autor (postado 21/11/2015). Acessado em 20/05/2016.

Este trabalho constou da primeira fase do projeto Telas Urbanas que teve início em 16 de novembro de 2015. A foto foi postada no dia 21 de novembro no facebook do autor, Efe Godoy. A imagem que se tem a seguir (figura 7) mostra o mesmo 
trabalho registrado em 17 de maio com uma intervenção sobreposta como se pode ver à esquerda da imagem, e nos detalhes na sequência.

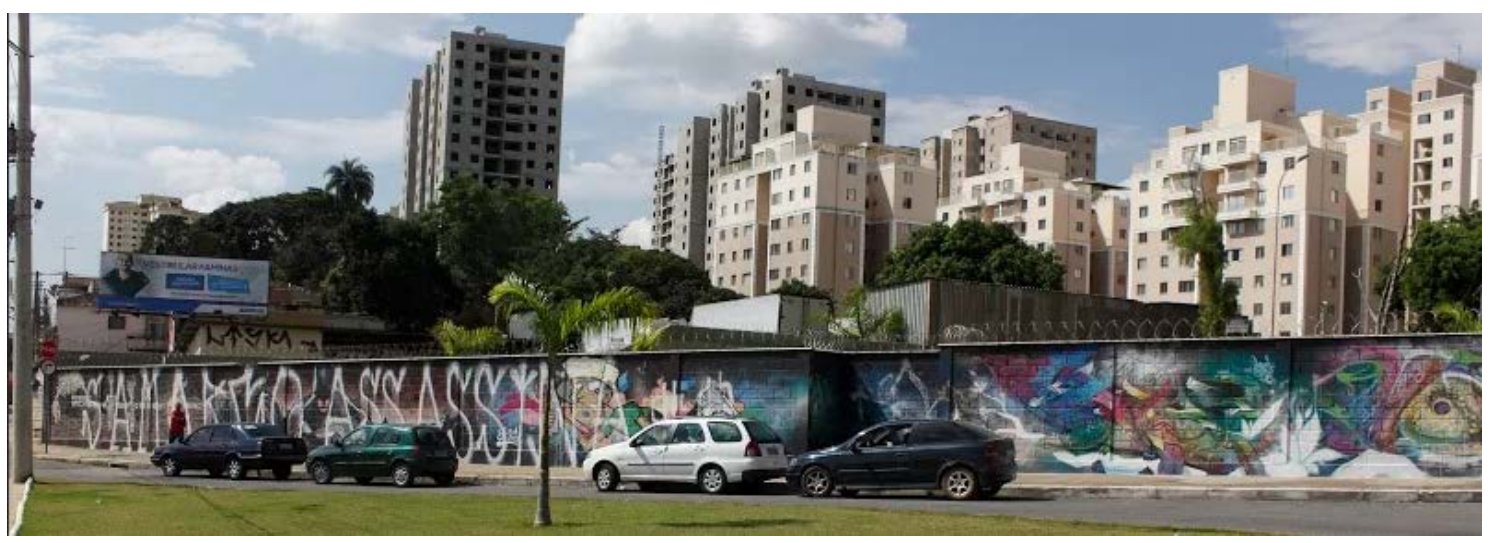

Figura 7 - Muro Telas Urbanas com intervenção sobreposta

Fonte: Foto das autoras - 17/05/16.

Na extensão do muro mostrado na figura 7, foram feitos três trabalhos como parte do projeto Telas Urbanas. O primeiro, à esquerda da foto, sofreu uma interferência com o texto "Samarco Assassina". No trabalho original constava a frase: "tudo então virou lama, desde o jardim da casa aos lençóis da cama" como mostrou a figura 6.
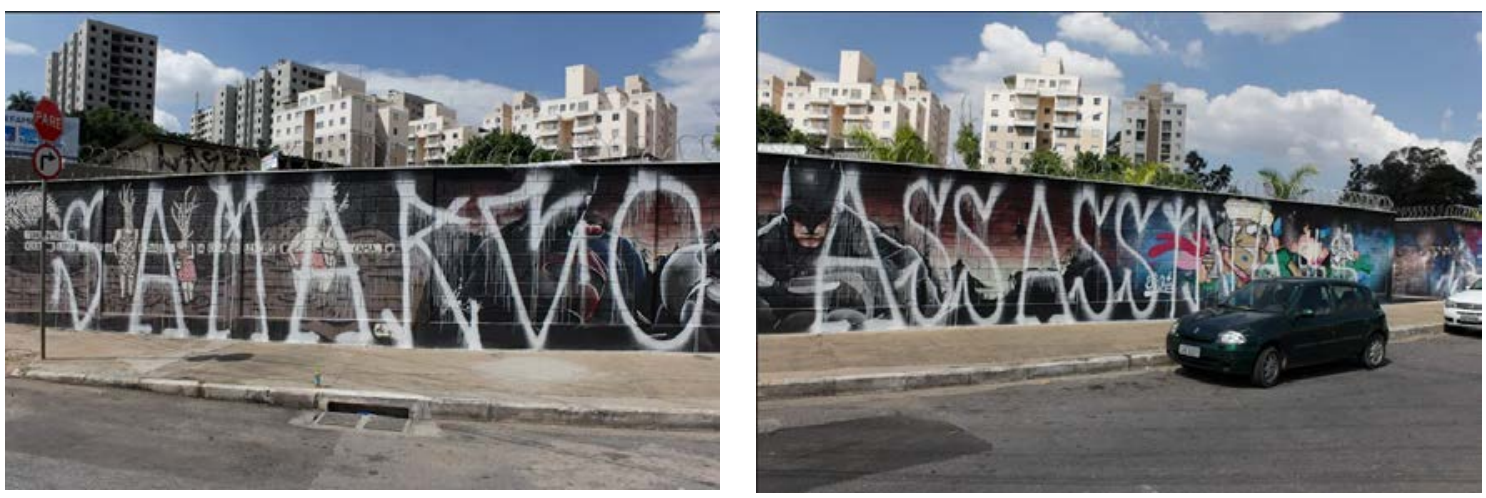

Figura 8 - Texto "Samarco Assassina" sobre pintura de projeto Telas Urbanas Fonte: Fotos das autoras - 17/05/16.

O manifesto refere-se à tragédia ocorrida em 05 de novembro de 2015 quando a Barragem do Fundão rompeu-se, na região de Mariana, Minas Gerais, espalhando grande quantidade de lama tóxica e rejeitos de mineração até o estado do Espírito Santo. A responsabilidade pelo acidente foi atribuída parcialmente à Samarco Mineração.

Interessante perceber que a mesma temática norteia as duas manifestações e interagem não só fisicamente, no espaço, mas também conceitualmente. 0 manifesto conjunto representa diferentes territórios, por meio de uma linguagem visual diversa, em que as mensagens se complementam. 


\section{CONCLUSÃO}

A discussão neste trabalho é um recorte de um projeto de pesquisa que visa a análise comparativa entre as intervenções gráfico-visuais realizadas no Baixo Centro de Belo Horizonte e os trabalhos selecionados e executados no Projeto Telas Urbanas, no entorno da Pampulha. A análise perpassa as questões territoriais, culturais e simbólicas que envolvem as criações nestes locais, e em que medida, o design se faz presente.

Neste artigo, busca-se iniciar uma discussão sobre a dinâmica das intervenções e manifestações visuais urbanas, pelos registros de ações expressas nas ruas da cidade dando a elas maior visibilidade, alcance e reflexão acerca dos significados estéticos, subjetivos e ideológicos que carregam.

O projeto encontra-se ainda em desenvolvimento, mas já é possível perceber as diferentes temáticas, estilos, linguagens e recursos característicos de seus autores, que por sua vez, representam territórios distintos na sociedade. As diferenças estão no processo e também nos resultados.

Por um lado, incursões são espontâneas, muitas vezes anônimas, marcadas pela irreverência e frequente crítica social. Surgem e desaparecem sobre os muros e fachadas da cidade com a mesma rapidez e efemeridade características do cotidiano urbano. Por outro lado, projetos como o Telas Urbanas, previamente inscritos e selecionados, são assinados e apoiados pelo poder público.

Em ambos os casos, estão sujeitos a novas intervenções, a novos significados, modificando constantemente a paisagem urbana e os diálogos que nela circulam visualmente. No entanto, há um dialogo na linguagem gráfica onde a arte e o design se fazem presentes e influenciam-se mutuamente.

\section{REFERÊNCIAS}

ARCHER, Michael. Arte contemporânea: uma história concisa. São Paulo: Martins Fontes, 2001.

BRISSAC, Nelson. Paisagens Urbanas. São Paulo: Senac, 2009, 4ำed.

BRISSAC, Nelson. Intervenções urbanas: Arte/cidade. São Paulo: Senac, 2012.

Carsalade, F. In: CASTRO, M.; FINGUERUT, S. Igreja da Pampulha: restauro e reflexões. Rio de Janeiro, 2006.

CANCLINI, Nestor. Culturas Híbridas: estratégias para entrar e sair da modernidade. Trad. Ana Regina Lessa; Heloísa Pezza Cintrão. 3. ed. São Paulo: EDUSP, 2001. (Ensaios Latino Americanos I).

JAYME, Juliana; TREVISAN, Eveline. Intervenções urbanas, usos e ocupações de espaços na região central de Belo Horizonte. Civitas, Porto Alegre v.12, n.2, p.359-377, 2012.

LEMOS, Cecília Borges. Antigas e novas centralidades: a experiência do consumo no centro tradicional de Belo Horizonte. Escola de Arquitetura da UFMG. Belo Horizonte, 2010.

PALLAMIN, Vera M. Arte urbana. São Paulo Região central (1945-1998). Obras de caráter temporário e permanente. São Paulo: Annablume: Fafesp, 2000. 
RIBEIRO, Rita; BELCHIOR, Camilo. Design e Arte: entre os limites e as interseções.

Contagem, Ed. do Autor, 2014.

ROBERTI, Marina Ferreira. Signos da cidade: o Lambe-Lambe enquanto arte. 2014. Monografia. (Graduação em Artes Visuais-Licenciatura) Escola de Design da Universidade do Estado de Minas Gerais, Belo Horizonte, 2014.

VELASCO, Mateu. Quando a arte de rua se transforma em design gráfico. 2013. 99 f. Dissertação (mestrado) - Pontifícia Universidade Católica do Rio de Janeiro, Curso de Pós-Graduação em Design. 